\title{
Projecting the release of carbon from permafrost soils using a perturbed parameter ensemble modelling approach
}

\author{
Andrew H. MacDougall and Reto Knutti \\ Institute for Atmospheric and Climate Science, ETH Zurich, Zurich, Switzerland \\ Correspondence to: Andrew H. MacDougall (andrew.macdougall@env.ethz.ch)
}

Received: 14 October 2015 - Published in Biogeosciences Discuss.: 10 December 2015

Revised: 26 February 2016 - Accepted: 3 April 2016 - Published: 12 April 2016

\begin{abstract}
The soils of the northern hemispheric permafrost region are estimated to contain 1100 to $1500 \mathrm{Pg}$ of carbon. A substantial fraction of this carbon has been frozen and therefore protected from microbial decay for millennia. As anthropogenic climate warming progresses much of this permafrost is expected to thaw. Here we conduct perturbed model experiments on a climate model of intermediate complexity, with an improved permafrost carbon module, to estimate with formal uncertainty bounds the release of carbon from permafrost soils by the year 2100 and $2300 \mathrm{CE}$. We estimate that by year 2100 the permafrost region may release between 56 (13 to 118) Pg C under Representative Concentration Pathway (RCP) 2.6 and 102 (27 to 199) Pg C under RCP 8.5, with substantially more to be released under each scenario by the year 2300. Our analysis suggests that the two parameters that contribute most to the uncertainty in the release of carbon from permafrost soils are the size of the non-passive fraction of the permafrost carbon pool and the equilibrium climate sensitivity. A subset of 25 model variants are integrated 8000 years into the future under continued RCP forcing. Under the moderate RCP 4.5 forcing a remnant near-surface permafrost region persists in the high Arctic, eventually developing a new permafrost carbon pool. Overall our simulations suggest that the permafrost carbon cycle feedback to climate change will make a significant contribution to climate change over the next centuries and millennia, releasing a quantity of carbon 3 to $54 \%$ of the cumulative anthropogenic total.
\end{abstract}

\section{Introduction}

Soils of the northern hemispheric permafrost region are estimated to contain between 1100 and $1500 \mathrm{PgC}$ of organic matter (Hugelius et al., 2014), roughly twice the quantity of carbon held in the pre-industrial atmosphere. As anthropogenic climate warming progresses, permafrost soils are expected to thaw exposing large quantities of organic matter to microbial decay, releasing $\mathrm{CO}_{2}$ and $\mathrm{CH}_{4}$ to the atmosphere (Schuur et al., 2015, 2008). Quantifying the strength and timing of this permafrost carbon cycle feedback to climate change has been a paramount goal of Earth system modelling in recent years (Zhuang et al., 2006; Koven et al., 2011; Schaefer et al., 2011; Schneider von Deimling et al., 2012; MacDougall et al., 2012; Burke et al., 2012, 2013; Schaphoff et al., 2013; Schneider von Deimling et al., 2015; Koven et al., 2015). However, large uncertainties in the physical and chemical properties of permafrost soils, as well as the simplified representation of permafrost processes in models, have lead to a large spread in the projected release of carbon from permafrost soils (Schuur et al., 2015, for recent review). These model estimates range from 7 to $508 \mathrm{PgC}$ released from permafrost soils by year 2100 (Zhuang et al., 2006; MacDougall et al., 2012). New assessments of the size and susceptibility to decay of the permafrost carbon pool have recently become available (Hugelius et al., 2014; Schädel et al., 2014). These new studies are the first to formally quantify the uncertainty of permafrost carbon pool metrics based on field measurements and laboratory experiments. These new explicit constraints on uncertainty make it possible to propagate these uncertainties through models to place formal constrains on the release of carbon from permafrost soil.

The objective of this study is to use the new constraints on the quantity and quality of the permafrost carbon pool to ex- 
plore key questions about the effect of the permafrost carbon pool on climate change. The questions we will investigate are as follows. (1) How much carbon will be released from permafrost soils by the years 2100 and 2300 , and what are the uncertainty bounds on these estimates? (2) Which of the uncertain parameters identified by Schädel et al. (2014) and Hugelius et al. (2014) contribute the most to uncertainty in the release of carbon from permafrost soils? (3) How much time will pass before the permafrost carbon pool comes into equilibrium with the anthropogenically perturbed climate? The following paragraphs briefly review how uncertainty is treated in the framework of Earth system models and the expected lifetime of anthropogenic climate change.

For the purposes of analyzing incubation experiments and modelling of soil respiration, soil carbon is conventionally conceptualized as a small number of carbon pools each with an characteristic resistance to decay (e.g. Schmidt et al., 2011). A recent analysis of incubation experiments conducted with permafrost soils broke the permafrost carbon into a small $(>5 \%)$ fast pool with an overturning time on the order of half a year, a moderate-sized slow pool $(\sim 5$ to $60 \%$ ) with an overturning time on the order of a decade, and a large passive pool with and overturning time estimated at over a century to greater than 2500 years (Schädel et al., 2014). This multi-pool framework will be used to inform the modelling of the release of carbon from permafrost soils presented in this manuscript.

In general there are two sources of uncertainty in modelling: structural uncertainty and parameter uncertainty (Smith, 2007). Structural uncertainty arises from the discrepancy between the system that the model describes and the system the model is meant to represent in the natural world. Parameter uncertainty arises from uncertainty in the value of a model parameters. This uncertainty can either be a measurement uncertainty when the parameter is measurable in the natural world or more difficult to define when the parameter represents an amalgam of many physical phenomena (e.g. Smith, 2007). A third source of uncertainty distinctive to Earth system modelling (but not exclusively so) is scenario uncertainty, that is, uncertainty about how emissions of $\mathrm{CO}_{2}$ and other radiatively active substances will evolve in the future. This kind of uncertainty is conventionally dealt with by forcing a model with multiple future scenarios (e.g. Moss et al., 2010). Here our experiments will focus on parameter and scenario uncertainty, with a brief intercomparison to similar experiments with different models to acknowledge structural uncertainty.

There are many methods to propagate uncertainty in model parameters into uncertainty in model outputs (Helton and Davis, 2003). Of commonly used methods only the Monte Carlo method and Latin hypercube sampling method do not require devising a statistical model of a physical model (Helton and Davis, 2003). In the Monte Carlo method uncertain model parameters are selected randomly from their probability distribution functions and randomly paired with other selected parameter values to form parameter sets (Helton and Davis, 2003). This method is conceptually simple and easy to implement but many thousands of model simulations are needed to comprehensively sample parameter space (e.g. Steinacher et al., 2013). The Latin hypercube method was designed to approximate the Monte Carlo method while using far fewer computational resources (McKay et al., 1979). In the Latin hypercube sampling method each probability distribution function is broken into intervals of equal probability. From each interval one parameter value is selected and matched randomly with other model parameter values selected in the same fashion to form parameter sets. In this method any number of model parameters can be perturbed without increasing the number of simulations. The number of required simulations is simply the number of equal-probability intervals selected (McKay et al., 1979). The Latin hypercube sampling method has been shown to capture parameter sets of low probability but of high consequence, which other sampling methods can miss (McKay et al., 1979). Latin hypercube sampling was originally developed by engineers to assess the safety of nuclear power plants (McKay et al., 1979) but has been used to explore the effect of parameter uncertainty on projections of future climate change (e.g. Forest et al., 2002; Collins et al., 2007; Shiogama et al., 2012).

Anthropogenic climate change will not cease in year 2100 (e.g. Clark et al., 2016) and the intrinsic timescale of decay of the passive component of the permafrost carbon pool implies that the permafrost carbon system will continue to evolve far into the future. Multi-millennial simulations of anthropogenic climate change suggest that the temperature change caused by the burning of fossil fuels will last for over 100000 years (Archer, 2005), a period of time long enough such that the permafrost carbon pool may come into equilibrium with the new climate regime. To explore the long-term fate of the permafrost carbon pool we have extended a sub-selection of model simulations 8000 years into the future.

\section{Methods}

\subsection{Model description}

The UVic ESCM is a climate model of intermediate complexity with a full three-dimensional ocean general circulation model coupled to a simplified moisture-energy balance atmosphere and thermodynamic-dynamic sea-ice model (Weaver et al., 2001). The model contains a full realization of the global carbon cycle. The terrestrial carbon cycle is simulated using the Top-down Representation of Interactive Foliage and Flora Including Dynamics (Triffid) dynamic vegetation model. Triffid is composed of five plant function types: broadleaf trees, needleleaf trees, shrubs, C3 grasses, and $\mathrm{C} 4$ grasses. These plant function types compete with one another for space in each grid cell based on the 
Lotka-Volterra equations (Cox et al., 2001). The simulated plants take up carbon through photosynthesis and distributed acquired carbon to plant growth and autotrophic respiration. Dead carbon is transferred to the soil carbon pool as litter fall and is distributed in the soil as an exponentially decreasing function of depth. Production of plant litter (and therefore new soil carbon) in Triffid is a function of temperature, plant function type, soil water availability, and atmospheric $\mathrm{CO}_{2}$ concentration (Cox et al., 2001; Booth et al., 2012).

The ocean inorganic carbon cycle is simulated following the protocols of the ocean carbon cycle model intercomparison project (Orr et al., 1999). Dissolved inorganic carbon is treated as a passive tracer by the model and carried throughout the ocean following ocean circulation (Weaver et al., 2001). Ocean biology is simulated using a nutrientphytoplankton-zooplankton-detritus ocean biology scheme (Schmittner et al., 2008). The slow feedback between ocean alkalinity and calcite dissolution is simulated using an oxygen only representation of respiration of organic matter in sediments (Archer, 1996). The simplified atmospheric scheme makes it possible to alter the equilibrium climate sensitivity of the model (Zickfeld et al., 2008). This is accomplished by altering the outgoing long-wave radiation to space as a function of global average near-surface air temperature anomaly (Zickfeld et al., 2008).

The version of the UVic ESCM used here is based on the frozen ground version documented in Avis et al. (2011) and Avis (2012). This version of the model has a deep subsurface extending down to $250 \mathrm{~m}$ depth and is composed of 14 vertical layers. These layers are of unequal thickness and become exponentially thicker with depth. The top eight layers $(10 \mathrm{~m})$ are hydraulically active and top six layers $(3.35 \mathrm{~m})$ are active in the carbon cycle. In the hydraulically active layers the subsurface porosity and permeability is prescribed based on the sand, silt, clay, and organic matter content of the grid cell. These gridded data are interpolated from the International Satellite Land Surface Climate Project Initiative II (Scholes and de Colstoun, 2012). The model accounts for the effect of soil valence forces on freezing point and the fraction of frozen and unfrozen water in soil is computed based on equations that minimize Gibbs free energy (Avis, 2012). The thermal conductivity of each soil layer is determined by the sand, silt, clay, water, ice, and organic carbon fraction of the layer (Avis, 2012).

\subsubsection{The permafrost carbon module}

A permafrost carbon module was added to the UVic ESCM by MacDougall et al. (2012) and described in detail in MacDougall (2014). For the experiments conducted in this study the permafrost carbon module has been overhauled and improved. The permafrost carbon pool is now prognostically generated within the model using a diffusion scheme based on that of Koven et al. (2009). This scheme is meant to approximate the process of cryoturbation on the vertical dis- tribution of soil carbon in permafrost affected soils. The scheme takes the form

$\frac{\partial C}{\partial t}=K_{v} \frac{\partial^{2} C_{\text {eff }}}{\partial z^{2}}$

where $C$ is the carbon concentration of the soil layer, $t$ is time, $z$ is the depth, $K_{v}$ is the diffusion parameter, and $C_{\text {eff }}$ is the effective carbon concentration of the layer. The diffusion parameter $K_{v}$ is altered as a function of depth:

$K_{v}= \begin{cases}K_{\mathrm{vo}}, & \text { for } z<z_{\mathrm{ALT}} \\ K_{\mathrm{vo}}\left(1-\left(\frac{z-z_{\mathrm{ALT}}}{(k-1) z_{\mathrm{ALT}}}\right)\right), & \text { for } z_{\mathrm{ALT}}<z<k z_{\mathrm{ALT}} \\ 0, & \text { for } z>k z_{\mathrm{ALT}}\end{cases}$

where $K_{\mathrm{vo}}$ is the cryoturbation mixing timescale, $z_{\mathrm{ALT}}$ is the thickness of the active layer, and $k$ is a constant here taken as 4. The original scheme of Koven et al. (2009) has been modified for use in the UVic ESCM. A drawback of the original scheme is that it uses diminishing rate of diffusion with depth to produce the diminishing concentration of permafrost soil carbon with depth. This implies that the scheme must never be in equilibrium with the surface concentration of carbon to maintain this vertical carbon gradient. When implemented this feature results in the size of the permafrost carbon pool being a function of the length of the model spin-up. From a model-design perspective this is a serious drawback, as (1) this will create a small model drift in atmospheric $\mathrm{CO}_{2}$ concentration, and (2) in general the size of the permafrost carbon pool should not be a function of the time needed for the ocean carbonate chemistry to reach equilibrium.

To fix this deficiency, diffusion is carried out with an effective carbon concentration which is related to the actual carbon concentration by

$C_{\mathrm{eff}}(i)= \begin{cases}C, & \text { for } i=1 \\ C_{\mathrm{eff}}=\frac{C}{S \Theta}, & \text { for } i>1\end{cases}$

where $i$ is the layer number, $S$ is the saturation factor, and $\Theta$ is the volumetric porosity of the layer. In the UVic ESCM the porosity of soil diminishes with depth and is a function of the sand, silt, and clay fraction of the layer. The factor $S$ was required to prevent permafrost soils from accumulating vastly more carbon than the estimated size of the permafrost carbon pool. The factor $S$ can take on values between 0 and 1 and is used to tune the size of the permafrost carbon pool.

In the present version of the UVic ESCM permafrost carbon is treated as an entirely separate soil carbon pool. Permafrost carbon is created when carbon is diffused across the permafrost table. The permafrost carbon can only be destroyed through simulated microbial respiration. This 
scheme allows the properties of the permafrost carbon to be prescribed. Permafrost carbon is also assigned an available fraction, which is effectively the combined fraction of the fast and slow soil carbon pools. When permafrost carbon decays the available fraction is reduced by the appropriate amount. The available fraction is increased as a function of time and soil temperature with a permafrost carbon transformation parameter determining the rate of change. This scheme effectively slowly transforms the passive fraction of the permafrost carbon into the slow soil carbon pool where it can be respired to $\mathrm{CO}_{2}$. Described mathematically the scheme is

$R_{\mathrm{p}}=\kappa_{\mathrm{p}} \mathrm{C}_{\mathrm{p}} A_{f} f_{\Theta} f_{T}$,

where $R_{\mathrm{p}}$ is permafrost carbon respiration, $\kappa_{\mathrm{p}}$ is the permafrost decay rate constant, $\mathrm{C}_{\mathrm{p}}$ is the permafrost carbon density, and $f_{\Theta}$ and $f_{T}$ are respectively moisture- and temperature-dependent functions. $A_{f}$ changes each time step:

$A_{f}^{t+1}=\mathrm{C}_{\mathrm{p}} A_{f}^{t}-R_{p}+\left(\kappa_{\mathrm{tf}} \mathrm{C}_{\mathrm{p}}\left(1-A_{f}^{t}\right) f_{\Theta} f_{T}\right)$,

where $\kappa_{\mathrm{tf}}$ is the rate constant for the transformation of carbon in the passive carbon pool into the slow carbon pool. Using this scheme the model can represent the large fraction of permafrost carbon that is in the passive carbon pool, while still allowing this passive pool to eventually decay.

\subsection{Comparison to data}

Figure 1 displays maps of the estimated soil carbon density in the top $3 \mathrm{~m}$ of soil in the northern hemispheric permafrost region as presented in Hugelius et al. (2014), compared to simulated soil carbon density in the top $3.35 \mathrm{~m}$ of the permafrost region as simulated by the UVic ESCM (using standard model parameter values). The maps show that the UVic ESCM generally simulates reasonable values for the density of carbon in the permafrost region but with substantial spatial biases. The model has too much carbon in northern fraction of the Fennoscandia peninsula, southern Alaska, and near the Lena River basin. The model does not capture the large permafrost carbon density in the Hudson Bay lowlands and permafrost (and therefore permafrost carbon) is absent from the Labrador peninsula, a bias common to many Earth system models (Koven et al., 2013). However, the model is able to capture some of the geographic features of the permafrost carbon pool including the high carbon density in northwestern Russia and the low carbon density in the eastern Canadian Arctic and Arctic archipelago.

The saturation factor from Eq. (3) was used to tune the total amount of carbon in the permafrost region such that in the default version of the model it matches the total from Hugelius et al. (2014) very closely. Therefore, in year 1995 the simulated permafrost region has $1035 \mathrm{PgC}$ in the top
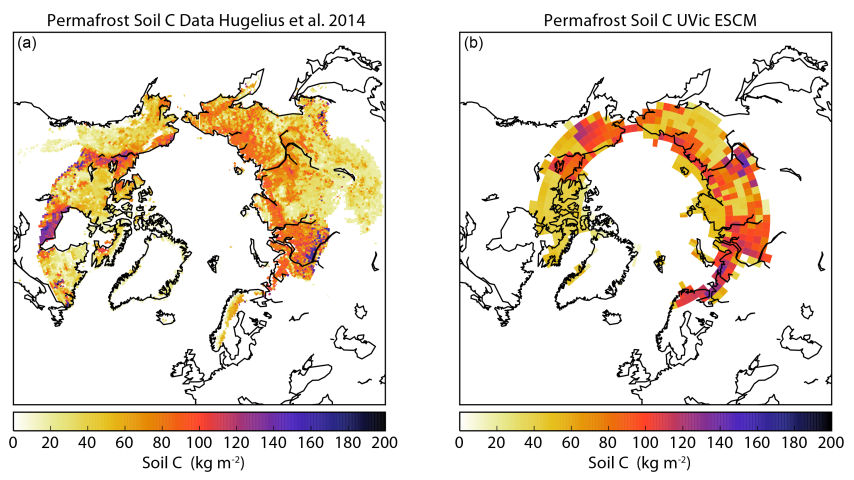

Figure 1. Comparison of the estimated soil carbon density in the top $3 \mathrm{~m}$ of soil in the northern hemispheric permafrost region from Hugelius et al. (2014) and soil carbon density in the top $3.35 \mathrm{~m}$ of soil in the permafrost region of the UVic ESCM. The permafrost region in the UVic ESCM is defined as the area where the model simulates at least one soil layer that is perennially frozen at the beginning of the model integration in year 1850. The model is able to capture the correct global total of soil carbon though tuning but with significant spatial biases.

$3.35 \mathrm{~m}$, equal to the best estimate for the carbon in the top $3 \mathrm{~m}$ of permafrost soil provided by Hugelius et al. (2014). Carbon held in perennially frozen soil layers makes up $49 \%$ of the carbon in the permafrost region in the UVic ESCM. This metric, which was not tuned, is very close to the estimate of $\sim 50 \%$ provided by Hugelius et al. (2014).

\subsection{Experiment design}

We have chosen to perturb four parameters that describe the permafrost carbon pool: (1) the quantity of soil carbon in the top $3 \mathrm{~m}$ of soil in the permafrost region, taken from Hugelius et al. (2014); (2) the permafrost decay rate constant $\kappa_{\mathrm{p}}$, computed from mean residence time of the slow permafrost soil carbon pool from Schädel et al. (2014); (3) the available fraction of permafrost carbon computed from the combined size of the fast and slow soil carbon pools in measured permafrost soils samples from Schädel et al. (2014); and (4) the passive pool transformation rate $\kappa_{\mathrm{tf}}$, estimated from Trumbore (2000). We also perturb two physical climate parameters: the climate sensitivity and the arctic amplification factor.

Besides the parameters we have chosen to perturb, many other parameters in the UVic ESCM could affect the magnitude of the release of carbon from permafrost soils. In particular parameters from the Triffid dynamic vegetation model that control net primary production determine the input of carbon into the soil, and therefore the net change is soil carbon in response to warming. However, for this study we have chosen to focus on uncertainty inherent to the permafrost carbon system instead of taking a global focus implied in perturbing the whole terrestrial carbon cycle (e.g. Booth et al., 2012). 
The quantity of carbon in permafrost soils is controlled by changing the saturation factor $S$ presented in Eq. (3). Calibration simulations were conducted with the UVic ESCM to derive a functional relationship between $S$ and the quantity of carbon in permafrost soils. The probability distribution function (PDF) for the permafrost carbon quantity (in the top $3 \mathrm{~m}$ of soil) was taken as a normal distribution with a mean of $1035 \mathrm{Pg} \mathrm{C}$ and a standard deviation of $75 \mathrm{Pg} \mathrm{C}$, taken from Hugelius et al. (2014). The permafrost carbon decay rate is derived from the mean residence time of the slow carbon pool in permafrost soils. The permafrost decay rate is taken to be normally distributed with a mean of 7.45 years and a standard deviation of 2.67 years, with values taken from Schädel et al. (2014). Schädel et al. (2014) reports the size of the fast, slow, and passive pool of soil organic carbon separately for organic, shallow mineral $(<1 \mathrm{~m})$, and deep mineral $(>1 \mathrm{~m})$ soils. Here these three categories of permafrost carbon have been combined to produce a single value for the available fraction. The sum of three weighted gamma distributions with each distribution respectively describing the PDF of the organic, shallow mineral, and deep mineral soils are used to describe the available fraction. The weights for the PDFs were derived from the relative fraction of permafrost soil carbon in organic, shallow mineral, and deep mineral soils from Hugelius et al. (2014). The parameter values for the PDFs were derived by fitting gamma functions to the data in Fig. 3 of Schädel et al. (2014). The passive pool transformation rate is very poorly constrained as the incubation experiments analyzed by Schädel et al. (2014) were unable to constrain the parameter's value (the contribution from the passive carbon pool was too small to be detected). The value of the parameter was estimated from the ${ }^{14} \mathrm{C}$ age of the passive carbon pool from midlatitude soils (Trumbore, 2000). The mean residence time at $5^{\circ} \mathrm{C}$ was estimated at 300 to 5000 years with a best guess of 1250 years yielding a passive pool transformation rate of $0.25 \times 10^{-10}$ to $4 \times 10^{-10} \mathrm{~s}^{-1}$, with a best guess of $1 \times 10^{-10} \mathrm{~s}^{-1}$. The PDF was taken as uniform in base-two log space.

Arctic amplification can be changed in the UVic ESCM by changing the meridional diffusivity of the simplified atmospheric model (Fyke et al., 2014; Fyke, 2011). Here the Arctic amplification factor was taken to be normally distribution with a mean of 1.9 and standard deviation of 0.2 (Serreze and Barry, 2011). Many studies have attempted to derive a PDF of equilibrium climate sensitivity (Collins et al., 2013, for recent summary) from model-based, observational, and paleoclimate evidence. Here we chose to use a PDF that captures the general features of these distributions with a mean of $3.25^{\circ} \mathrm{C}$ for doubling of $\mathrm{CO}_{2}$ and the 5th and 95th percentile 1.7 and $5.2{ }^{\circ} \mathrm{C}$ respectively (Olson et al., 2012). The PDFs for all six perturbed parameters are shown in Fig. 2.

The Latin hypercube sampling, described in the introduction, was used to create the parameter sets. Each PDF was sampled from 25 equal-probability intervals and the value selected from each interval was randomly matched to one
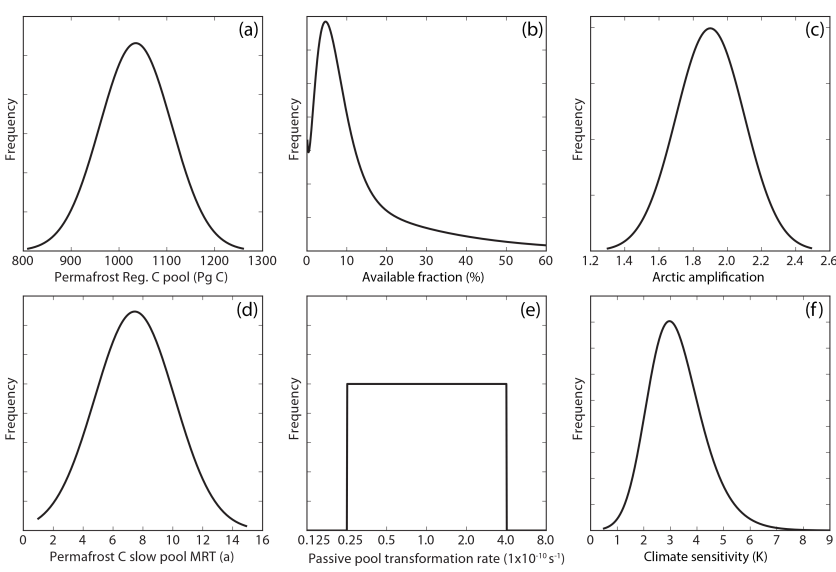

Figure 2. Probability distribution functions of the six parameters perturbed in this study. Panel (b) is the sum of three weighted gamma functions (one each for organic soil, shallow, and deep mineral soil). Panel (e) has a logarithmic scale. MRT is mean residence time.

of the values selected from each of the other PDFs to create a "cube" containing 25 parameter sets. This sampling was repeated 10 times to create 10 cubes for a total of 250 model variants. Each of these variants was spun up for 5000 years under estimated year 1850 forcing to generate the permafrost carbon pool. Each model variant was forced with historical forcing followed by each of the four representative concentration pathways (RCPs) used in the fifth assessment report of the Intergovernmental Panel on Climate Change (IPCC AR5). The simulations were carried out with prescribed atmospheric $\mathrm{CO}_{2}$ concentrations and compatible anthropogenic $\mathrm{CO}_{2}$ emissions were diagnosed as a residual of the carbon cycle.

The old permafrost carbon capable version of the UVic ESCM was able to quantify the previously unaccounted for temperature effect of the permafrost carbon feedback by comparing model simulations with and without permafrost carbon (MacDougall et al., 2012). This has become much more difficult with the introduction of the permafrost carbon pool diffusion module. The soil carbon diffusion scheme causes the active layer to accumulate more soil carbon than in the model version without a prognostically generated permafrost soil carbon pool. Consequently we can no longer easily "turn off" the permafrost carbon. Therefore we have chosen to conduct experiments which quantify the permafrost carbon feedback in terms of carbon released from permafrost affected soils. As carbon released from permafrost soil displaces fossil fuel carbon in the carbon budget (MacDougall et al., 2015), we feel this is the most policy-relevant metric.

Twenty-five model variants (one cube) were projected 8000 years into the future under continued RCP 4.5 and 8.5 forcing. For this experiment only the four permafrost carbon parameters were perturbed, and climate sensitivity and arctic amplification were held at their model default values. 
Table 1. Release of carbon from permafrost soils by year 2100 and 2300 for each RCP scenario. Ranges are 5th to 95th percentiles. All values are in $\mathrm{PgC}$.

\begin{tabular}{lcccc}
\hline & $\begin{array}{c}\text { Mean } \\
\text { (year 2100) }\end{array}$ & $\begin{array}{c}\text { Range } \\
\text { (year 2100) }\end{array}$ & $\begin{array}{c}\text { Mean } \\
\text { (year 2300) }\end{array}$ & $\begin{array}{c}\text { Range } \\
\text { (year 2300) }\end{array}$ \\
\hline RCP 2.6 & 56 & $(13$ to 118) & 91 & $(32$ to 175) \\
RCP 4.5 & 71 & $(16$ to 146) & 149 & $(45$ to 285) \\
RCP 6.0 & 74 & $(15$ to 154) & 204 & $(63$ to 371) \\
RCP 8.5 & 101 & $($ (27 to 199) & 376 & $(159$ to 587) \\
\hline
\end{tabular}

For each scenario the models were forced with prescribed atmospheric $\mathrm{CO}_{2}$ concentration until peak $\mathrm{CO}_{2}$ concentration was reached (year 2150 for RCP 4.5 and year 2250 for RCP 8.5). Thereafter the simulated $\mathrm{CO}_{2}$ emissions were set to 0 and atmospheric $\mathrm{CO}_{2}$ was allowed to freely evolve. All other RCP forcings follow their prescribed trajectory until year 2300 and subsequently are held constant. The simulations were continued until the year 10000 of the common era, 8000 years into the future. Expecting non- $\mathrm{CO}_{2}$ forcings to be constant for thousands of years following year 2300 is highly idealized, but this method was seen as the simplest approach for evaluating the long-term response of the permafrost carbon pool to anthropogenic forcing.

\section{Results}

\subsection{Release of carbon to 2300}

The release of carbon from permafrost soils for each RCP and for each of the 250 model variants is shown in Fig. 3. Average values and ranges for this quantity are given for all RCPs in Table 1. Model results in this section are quoted as the mean value of all model variants with the 5th and 95th percentile range in brackets. This is equivalent to the "very likely" range from IPCC AR5, although the numbers here are of course conditional on the model structure and parameter PDFs chosen. By year 2100 the model estimates that 56 (13 to 118) Pg C will be released under RCP 2.6 and 102 (27 to 199) Pg C released under RCP 8.5. By year 2300 the model estimates that 91 ( 32 to 175) Pg C will be released under RCP 2.6 and 376 (159 to 587) Pg C released under RCP 8.5. These results are generally consistent with the inter-model range of 37 to $174 \mathrm{Pg} \mathrm{C}$, mean of $92 \mathrm{Pg} \mathrm{C}$, by year 2100 under RCP 8.5 from Schuur et al. (2015).

The emission rate of $\mathrm{CO}_{2}$ from permafrost soils is shown in Fig. 4 and peak emissions for each RCP given in Table 2. Peak emissions under RCP 2.6 is 0.56 (0.13 to 1.29$)$ and under RCP 8.5 is 1.05 ( 0.28 to 2.36 ) $\mathrm{PgC} \mathrm{a}^{-1}$. The timing of peak emissions of $\mathrm{CO}_{2}$ from permafrost soils varies by model variant and scenario followed (Fig. 4) but generally occurs in the mid- to late 21 st century or early 22 nd century in the case of RCP 6.0. The emission rate from permafrost soils is a function of both the rate of permafrost thaw and the depletion
Table 2. Peak emission rate of carbon from permafrost soils for each RCP scenario. Ranges are 5th to 95th percentiles. All values are in $\mathrm{PgCa}^{-1}$.

\begin{tabular}{lcc}
\hline & Mean & Range \\
\hline RCP 2.6 & 0.56 & (0.13 to 1.29$)$ \\
RCP 4.5 & 0.66 & (0.16 to 1.57$)$ \\
RCP 6.0 & 0.75 & $(0.19$ to 1.59$)$ \\
RCP 8.5 & 1.05 & (0.28 to 2.36) \\
\hline
\end{tabular}

of the available fraction of permafrost carbon in thawed soils. The similar trajectories of emissions in the early to mid-21st century for the different RCP scenarios is consistent with the lag between forcing and response of the permafrost system. These simulated peak emission rates are of similar magnitude to modern land use change emissions, $0.9 \pm 0.8 \mathrm{PgC}$ $\mathrm{a}^{-1}$ averaged over the year 2000 to 2011 period (Ciais et al., 2013). Even in the most extreme bound emissions from permafrost carbon are projected to be far lower than modern $\mathrm{CO}_{2}$ emissions from fossil fuel burning and cement production (9.5 $\pm 0.8 \mathrm{Pg} \mathrm{C} \mathrm{a}^{-1}$ in 2011; Ciais et al., 2013).

The permafrost carbon feedback's effect on climate change will ultimately be determined by how large the release of carbon from permafrost soils is relative to the cumulative fossil fuel emissions (MacDougall and Friedlingstein, 2015). This notion follows from the near-linear relationship between cumulative emissions of $\mathrm{CO}_{2}$ and change in global temperature (Matthews et al., 2009; Gillett et al., 2013), a relationship that emerges from the interaction of atmospheric and oceanic processes with the land surface source or sink effectively acting in the same manner as fossil fuel emissions (MacDougall and Friedlingstein, 2015). The release of carbon from permafrost soils relative to the diagnosed cumulative emissions for each model variant and RCP scenarios is shown in Fig. 5. The relative emissions are highest under RCP 2.6 where emissions from permafrost soil are 13 (2 to 39 ) $\%$ of fossil fuel emissions in 2100 and 21 (5 to 54) \% of fossil fuel emissions by 2300 . Under RCP 8.5 carbon released from permafrost soils is only 2 (0.5 to 5$) \%$ of fossil fuel emissions in 2100 and 8 ( 3 to 14 ) \% of fossil fuel emission by 2300 . RCPs 4.5 and 6.0 fall between these bounds with 7 ( 1 to 16 ) and 4 (1 to 10)\% respectively by 2100 and 14 (3 to 29 ) and 12 (3 to 24 ) \% respectively by 2300 . These results suggest the permafrost carbon feedback to climate change will be more important in a relative sense to the magnitude of climate change in scenarios with substantial mitigation, consistent with previous studies (e.g. MacDougall et al., 2012).

\subsection{Reduction in permafrost area}

In year 1850 the UVic ESCM has a northern hemispheric permafrost area (including the Tibetan plateau) of 14.87 million $\mathrm{km}^{2}$, comparing well to the total of continuous 

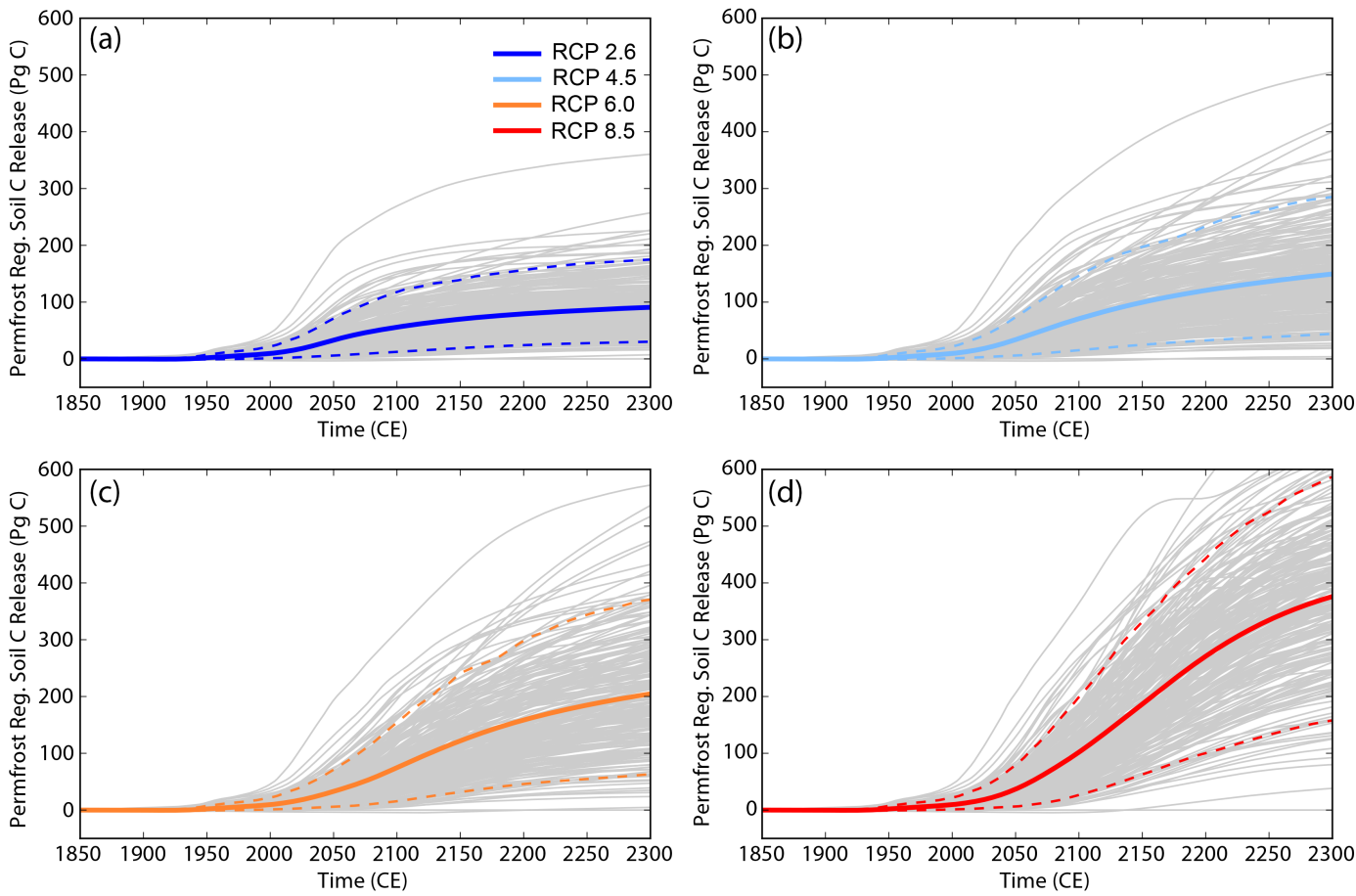

Figure 3. Release of carbon from the permafrost region for all 250 model variants (grey lines) and four RCP scenarios. Mean for each scenario shown with think solid line. Fifth and 95th percentiles shown with dashed lines.
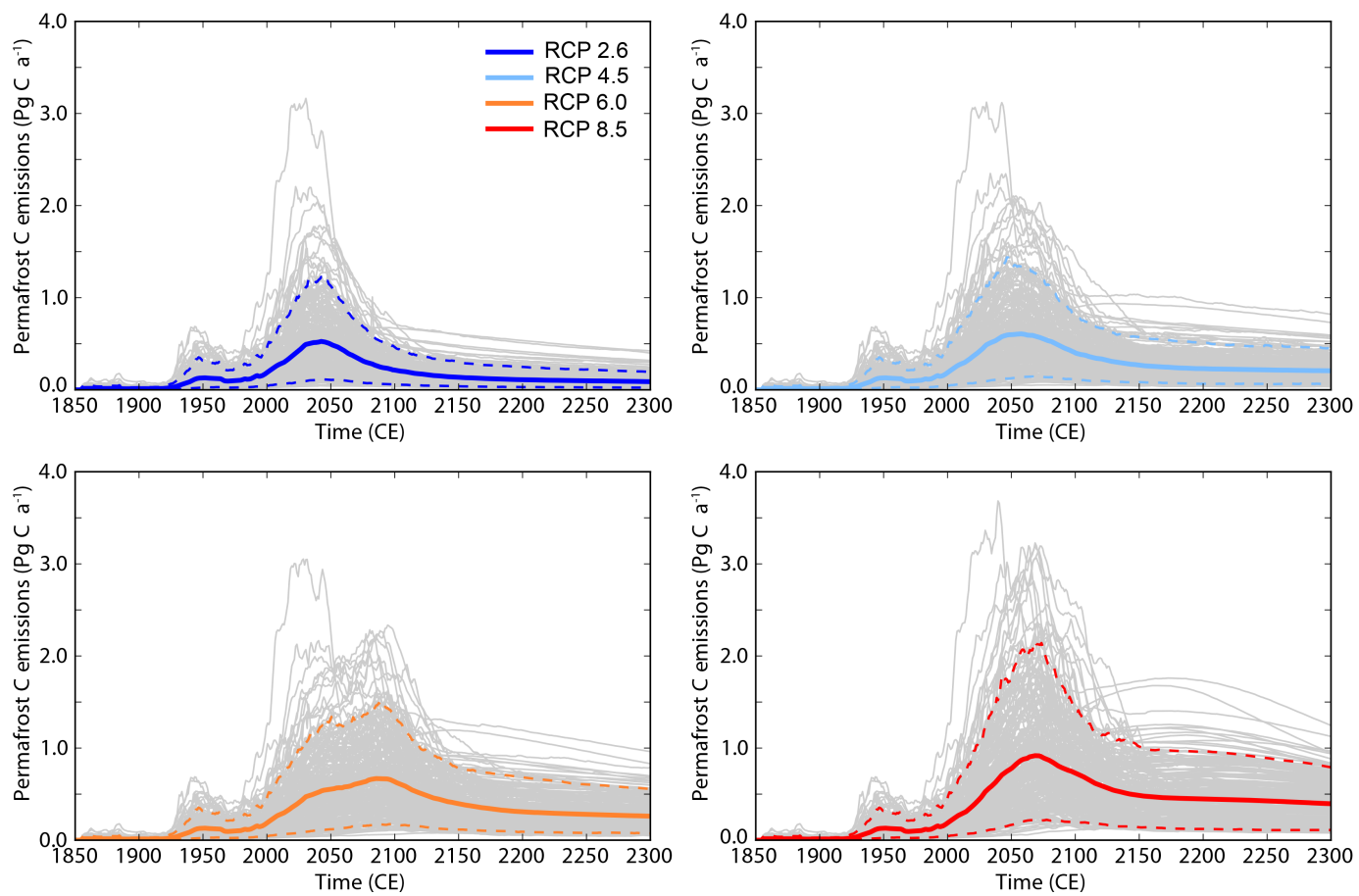

Figure 4. Emission of carbon from permafrost soils for each model variant (grey lines) and each RCP scenario. Mean for each scenario shown with think solid line. Fifth and 95th percentiles shown with dashed lines. 
Table 3. Reduction in the size of the northern hemispheric permafrost region by year 2100 and 2300 relative to year 1850 (14.9 million $\mathrm{km}^{2}$ ). Ranges are 5 th to 95 th percentiles. All values are in million of $\mathrm{km}^{2}$.

\begin{tabular}{ccccc}
\hline & $\begin{array}{c}\text { Mean } \\
\text { (year 2100) }\end{array}$ & $\begin{array}{c}\text { Range } \\
\text { (year 2100) }\end{array}$ & $\begin{array}{c}\text { Mean } \\
\text { (year 2300) }\end{array}$ & $\begin{array}{c}\text { Range } \\
\text { (year 2300) }\end{array}$ \\
\hline RCP 2.6 & 5.9 & $(2.2$ to 8.4) & 4.8 & $(1.7$ to 8.1) \\
RCP 4.5 & 7.6 & $(3.8$ to 9.6) & 8.8 & $(4.7$ to 11.3) \\
RCP 6.0 & 8.3 & $(4.8$ to 9.7) & 10.3 & $(7.3$ to 11.8) \\
RCP 8.5 & 9.3 & $(7.5$ to 9.9) & 11.7 & $(10.3$ to 12.1) \\
\hline
\end{tabular}

and discontinuous permafrost area in the natural world (e.g. Tarnocai et al., 2009). By year 2100 the northern hemispheric permafrost area has been reduced by 5.91 (2.25 to 8.43) million $\mathrm{km}^{2}$ under RCP 2.6 and 9.30 (7.49 to 9.90) million $\mathrm{km}^{2}$ under RCP 8.5. By 2300 a small recovery of permafrost area occurs under RCP 2.6 with a net reduction from year 1850 of 4.78 (1.71 to 8.13 ) million $\mathrm{km}^{2}$, while the loss of permafrost area continues until at least year 2300 under the other RCPs (Table 3).

\subsection{Parameter uncertainty}

The relative importance of uncertainty from each perturbed model parameter to the overall uncertainty can be evaluated by computing the correlation coefficient between the parameter value and the value of some model output (e.g Shiogama et al., 2012). In Fig. 6 the correlation between each of the six perturbed model parameters and release of carbon from permafrost soils under RCP 8.5 by 2100 is shown. This particular metric was chosen as it has become the benchmark to compare simulations of the permafrost carbon feedback (e.g. Schuur et al., 2015). The two highest correlations are for the initial available fraction with an $\mathrm{R}$ value of 0.78 and climate sensitivity with an $\mathrm{R}$ value of 0.51 . Correlations for the other perturbed parameters are less that 0.13 . These correlations suggest that reducing the uncertainty in the release of carbon from permafrost soils by 2100 requires better quantification of the size of the fast and slow carbon pools in permafrost soils. Also important is reducing the uncertainty in climate sensitivity, already a paramount, if intractable, problem in climate science (e.g. Collins et al., 2013; Knutti and Hegerl, 2008). The four other perturbed parameters are relatively unimportant for reducing uncertainty to year 2100 .

Correlations were also conducted between each model perturbed parameter value and release of carbon from permafrost soils by 2300. By 2300 the importance of the initial available fraction has decreased and has an $\mathrm{R}$ value of 0.36 , the correlation with permafrost carbon transformation rate has increased to an $\mathrm{R}$ value of 0.43 , and the correlation with climate sensitivity has increased to 0.64 . The correlations with initial quantity of carbon in the permafrost region, permafrost carbon decay rate, and arctic amplification remain weak by year 2300 , at $0.13,0.02$, and 0.11 respectively.
These results demonstrate that the relative importance of uncertainty in parameters changes depending on the time frame of interest.

The low sensitivity of the release of carbon from permafrost soils to the value of Arctic amplification appears counterintuitive. However, most of the carbon held in the permafrost region is held in the region's southern extent (Fig. 1b), while Arctic amplification has the greatest effect over the Arctic ocean, Greenland ice sheet, and Canadian Arctic Archipelago where there is little simulated permafrost carbon.

Overall these results are encouraging as the most important factor for determining release of carbon from permafrost soils in the next century, the size of the permafrost carbon fast and slow pools, can be measured with incubation experiments (e.g. Schädel et al., 2014). A dedicated field campaign and set of laboratory experiments to collect samples of permafrost carbon in optimal locations and conduct incubation experiments at the optimal temperatures could therefore significantly reduce uncertainty in the strength of the permafrost carbon feedback to climate change.

\subsection{Temperature sensitivity of permafrost carbon release}

Climate change mitigation targets are often framed in terms of some global temperature change threshold not to be breached (e.g. Knutti and Rogelj, 2015). Therefore examining the relationship between global temperate change and the release of carbon from permafrost soils is of interest. Figure 7 shows the correlation between change in global temperature and the release of carbon from the permafrost soils for all model variants and RCPs at years 2100, 2200, and 2300. The figure shows that there is a clear correlation between the two quantities at all three time horizons. However, the slope of the correlation evolves in time from 24 in 2100 to 39 in 2200 and $47 \mathrm{PgC} \mathrm{K}^{-1}$ in 2300 . These correlations demonstrate a key feature of the permafrost carbon system: the long time lag between forcing and response. That is, if fossil fuel emissions are eliminated and global temperature stabilizes, permafrost soils are expected to continue to release carbon for a long time.

\subsection{Multi-millennial experiment}

The evolution of global mean temperature and atmospheric $\mathrm{CO}_{2}$ concentration for the multi-millennial experiments are shown in Fig. 8. Under continued non- $\mathrm{CO}_{2} \mathrm{RCP} 4.5$ forcing and with zero $\mathrm{CO}_{2}$ emissions, $\mathrm{CO}_{2}$ concentration falls until about the 28th century under all model variants and thereafter drifts slowly up or down depending on model variant. Under this scenario temperature continues to increase following cessation of emissions, becomes relatively stable for several centuries, experiences a period of renewed rapid warming in the late third millennium, and then becomes stable there- 

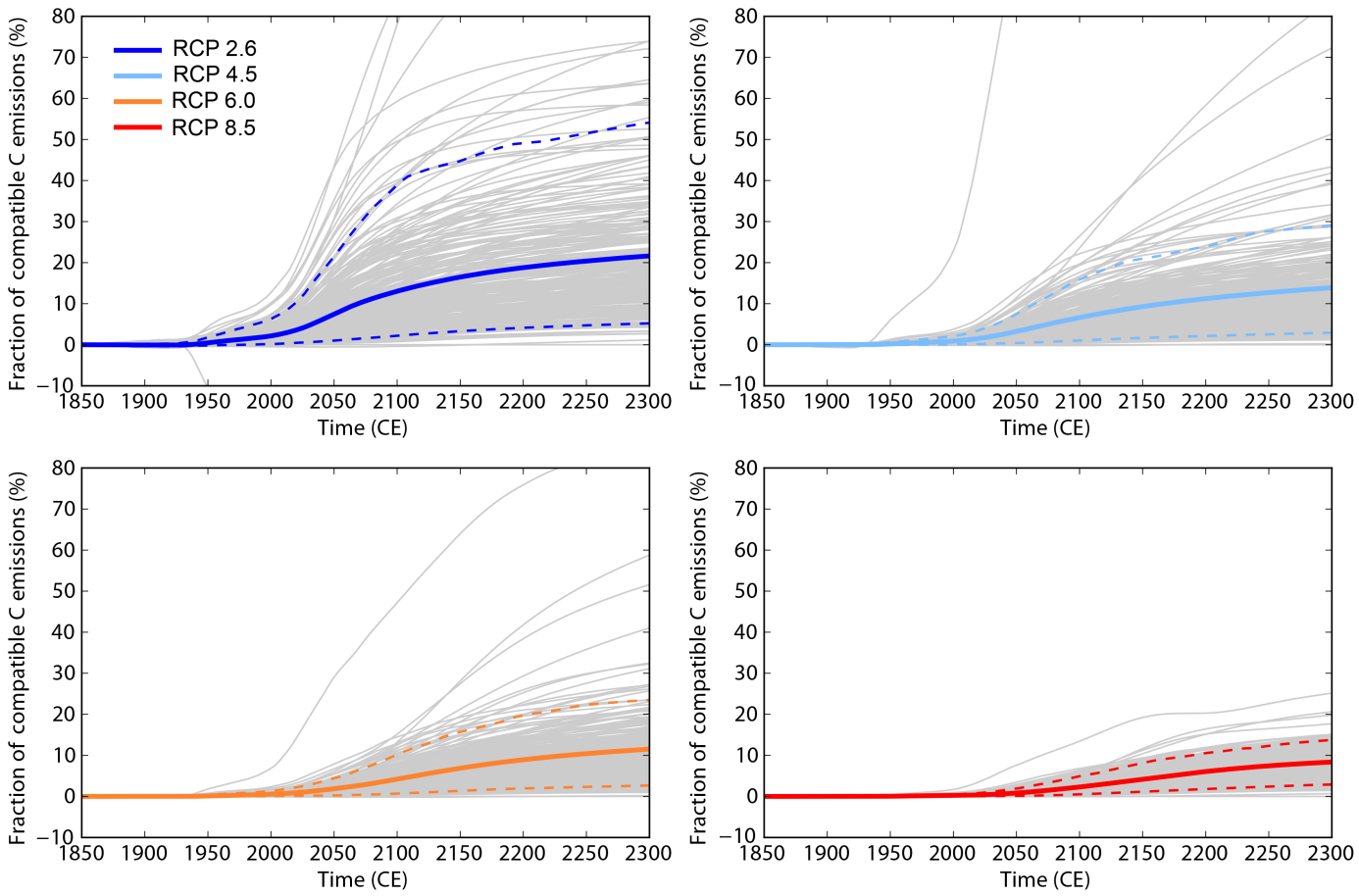

Figure 5. Cumulative emissions from permafrost soils relative to diagnosed compatible emissions for each model variant (grey lines) and each RCP scenario. Mean for each scenario shown with think solid line. Fifth and 95th percentiles shown with dashed lines. Note that under scenarios with lower emissions permafrost carbon emissions are larger relative to fossil fuel emissions.
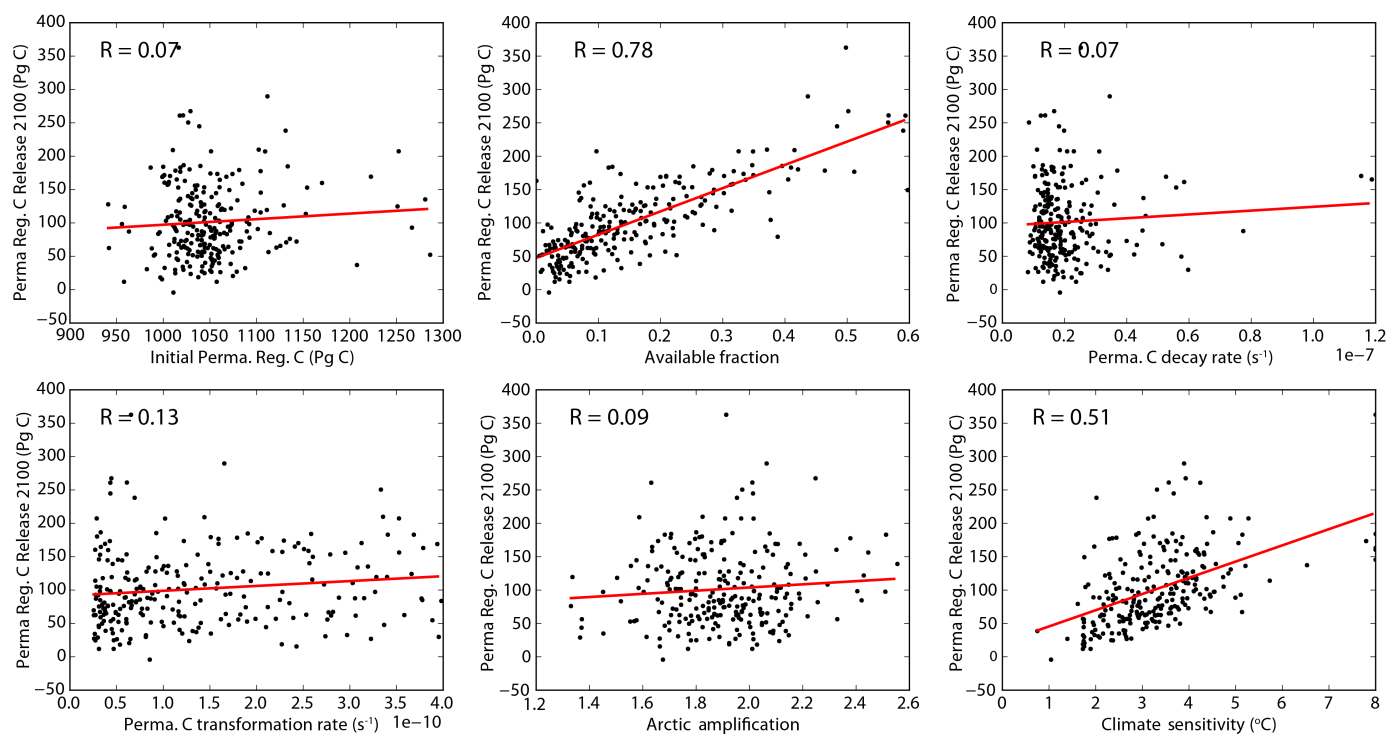

Figure 6. Correlation between release of carbon from the permafrost region in year 2100 under RCP 8.5 and value of perturbed model parameters. Red line is line of best fit and $\mathrm{R}$ is correlation coefficient.

after. Under continued RCP 8.5 forcing atmospheric $\mathrm{CO}_{2}$ declines monotonically after cessation of emissions, reaching a concentration below $1600 \mathrm{ppm}$ by year $10000 \mathrm{CE}$. Temperature continues to slowly increase following cessation of emissions, indicating that radiative forcing from atmospheric $\mathrm{CO}_{2}$ is declining to slowly to compensate for the unreal- ized warming of the system (e.g. MacDougall et al., 2013; Frölicher et al., 2014). Temperature change reaches a peak in the fifth millennium CE in these simulations. Thereafter, temperature begins a slow decline. The long-term evolution of temperature and atmospheric $\mathrm{CO}_{2}$ shown in these experiments is somewhat different from that in Eby et al. (2009), 

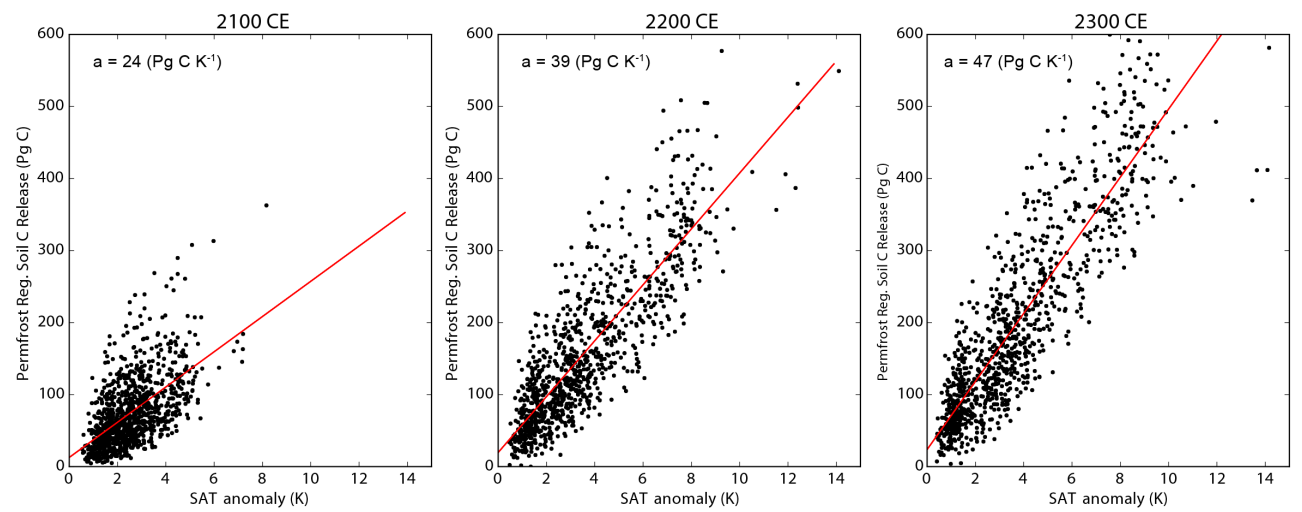

Figure 7. Correlation between release of carbon from the permafrost region and change in global temperature at years 2100,2200 , and 2300 CE. Red line is line of best fit and $a$ is the slope of this line.
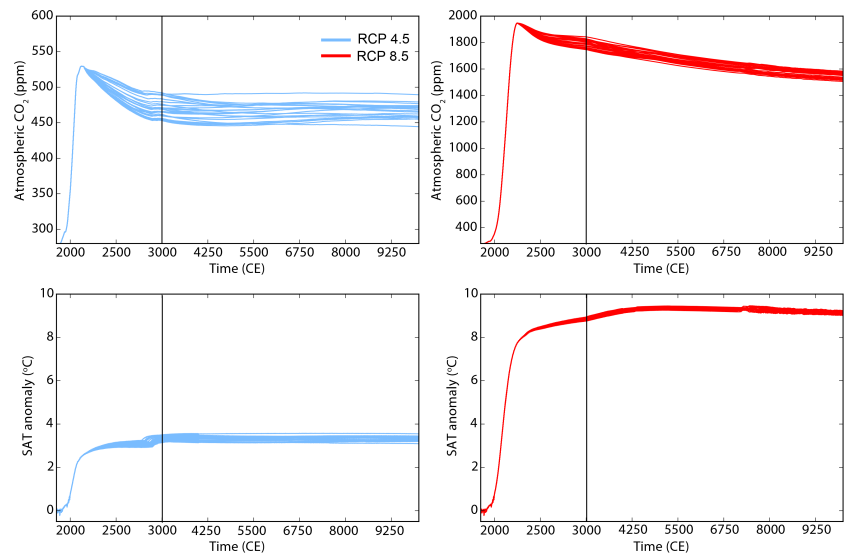

Figure 8. Evolution of $\mathrm{CO}_{2}$ and surface air temperature (SAT) anomaly under continued RCPs 4.5 and 8.5 forcing until common era year 10000 (8000 years into the future). Vertical black line indicates change in horizontal scale.

who showed larger declines in temperature and atmospheric $\mathrm{CO}_{2}$ for comparable cumulative emissions and time frame. The continued existence of non- $\mathrm{CO}_{2}$ forcing in these scenarios and the inclusion of the permafrost carbon module are probable causes of the differences between that study and the present study, as both studies use similar versions of the UVic ESCM.

The response of the permafrost carbon pool to millennia of anthropogenically enhanced temperatures varies by scenario followed. Under RCP 8.5 the pool monotonically declines with time, with the rate of decline varying by parameter set (Fig. 9). By the year $10000 \mathrm{CE}$ most of the model variants asymptote toward a carbon pool of about $10 \mathrm{Pg} \mathrm{C}$, held around the fringes of Antarctica. Under RCP 4.5 the permafrost carbon pool begins a recovery before the year 3000 CE (Fig. 9), with permafrost soil carbon reaching a nadir in the year 2411 (2254 to 2605) CE. Some of the parameter sets show renewed reduction in permafrost carbon
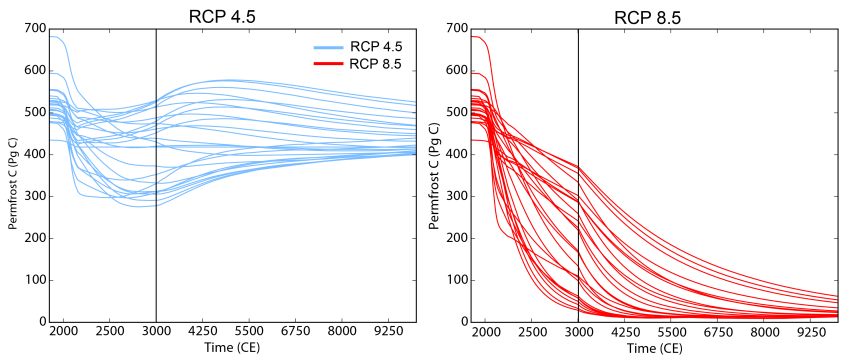

Figure 9. Evolution of permafrost soil carbon pool under continued RCPs 4.5 and 8.5 forcing until common era year 10000 (8000 years into the future). Vertical black line indicates change in horizontal scale. Under RCP 4.5 forcing the permafrost carbon pool undergoes a recovery in the late third millennium and under RCP 8.5 forcing declines toward a near-zero value.

about 2000 years after the recovery begins. The origin of this recovery, despite continued elevated global temperatures, is the creation of a large permafrost carbon pool in the Canadian Arctic archipelago and the high Russian Arctic as shown in Fig. 10. This region is thought to contain very little soil carbon in the modern climate (see Fig. 1), a feature of the system that is captured by the model (Fig. 1b). Under RCP 4.5 these regions accumulate large permafrost carbon pools as they remain permafrost bound but with much higher net primary productivity from overlying vegetation. The simulations suggest that the ultimate fate of the permafrost carbon pool is highly contingent on scenario followed.

\section{Discussion}

The release of carbon in these simulations is smaller than the previous estimate using an earlier version of this model (MacDougall et al., 2012). That study estimated that release of carbon from permafrost soils of 174 (68 to 508) Pg C by 2100. The comparable range from this study is 102 (27 to 199) Pg C. The greatest difference between these two ver- 
sions of the UVic ESCM is the treatment of the passive soil carbon fraction of the permafrost carbon pool. The recent analysis of Schädel et al. (2014) showed that the passive pool makes up a larger fraction of permafrost carbon than the few studies available in 2011 had suggested when the simulations of MacDougall et al. (2012) were performed. Incorporating these new data into the model has reduced the estimated released of carbon from permafrost soils by year 2100 by about half.

The study most similar to the present study is that of Schneider von Deimling et al. (2015), which used a complex box model of the permafrost carbon system to conduct perturbed model ensemble simulations. That study estimated the release of carbon from thawed permafrost soil only and does not compute the release of carbon from the historic active layer. Schneider von Deimling et al. (2015) estimate that under RCP 2.636 (20 to 58, $68 \%$ range) Pg C will be released by 2100 . The comparable $68 \%$ range from the experiments conducted with the UVic ESCM (accounting only for release of permafrost carbon and not for carbon released from the historic active layer) is 46 (19 to $75,68 \%$ range) $\mathrm{Pg} \mathrm{C}$ by 2100. Under RCP 8.5 Schneider von Deimling et al. (2015) estimated that 87 (42 to $141,68 \%$ range) $\mathrm{Pg} \mathrm{C}$ would be released from thawed permafrost by 2100 compared to 75 (31 to $120,68 \%$ range) $\mathrm{Pg} \mathrm{C}$ in the UVic ESCM. The study of Schneider von Deimling et al. (2015) and the present study use radically different modelling structures but converge on very similar estimates of the release of carbon from permafrost soil. This suggests that parameter uncertainty dominates the uncertainty in projecting the release of carbon from permafrost soils and that a perturbed parameter approach can successfully capture the uncertainty in this model component. The inter-model range from a recent review paper on the permafrost carbon feedback (Schuur et al., 2015) was 92 (37 to 174) Pg C under RCP 8.5, which compares favourably to the $90 \%$ range in the present study of 102 (27 to 199) Pg C. Overall it appears that modelling studies of release of carbon from permafrost soils are converging toward a common estimate of the strength of the feedback.

There are many processes that affect the thaw of permafrost and decay of permafrost carbon that are not accounted for in the UVic ESCM. The UVic ESCM has permafrost carbon only in the top $3.35 \mathrm{~m}$ of soil and therefore does not account for the substantial quantity of carbon held below $3 \mathrm{~m}$ in deltaic deposits $91 \pm 52 \mathrm{Pg} \mathrm{C}$ and the Yedoma region $181 \pm 54 \mathrm{Pg} \mathrm{C}$ (Hugelius et al., 2014). Other modelling studies suggest that the contribution from these deep soil deposits will be small in the coming centuries (e.g. Schneider von Deimling et al., 2015) but this pool of carbon would likely affect the results of our multi-millennial experiments. The UVic ESCM accounts for only two of the four mechanisms of permafrost thaw - active-layer thickening and talik formation - and does not simulate thermokarst development or soil erosion. The UVic ESCM does not simulate the production of methane from thawed soils. As warm-

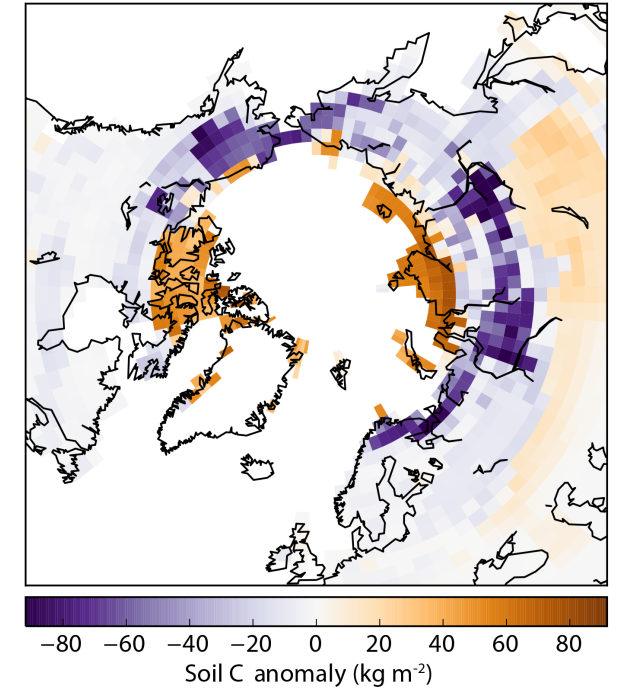

Figure 10. Difference between soil carbon density in the Northern Hemisphere between 1875 and 5250 CE under continued RCP 4.5 forcing. A large permafrost carbon pool has developed in the high arctic by year 5250 .

ing from methane is proportional to the rate of emissions and not cumulative emissions (e.g. Pierrehumbert, 2014), it is unlikely that plausible rates of emission of methane from thawed permafrost soils will contribute cataclysmically to climate change (e.g. Schuur et al., 2015). The global dynamic vegetation scheme used by the UVic ESCM does not account for the effect of nutrient limitations on plant growth. The decay of organic matter in permafrost soils releases nutrients into the soils which presumably should enhance plant growth (e.g. Schuur et al., 2008), representing an unaccounted for negative feedback. We have not quantified all of the parameter uncertainty that could affect the simulated permafrost carbon system. In particular the parameters in Triffid that control net primary productivity will determine the flow of organic carbon into soils and therefore the net release of carbon from permafrost soils. Transport of permafrost carbon from soils to surface waters as dissolved organic carbon (DOC) is a process that is unaccounted for in the UVic ESCM. Field studies in Arctic regions suggest that once DOC is transported to the surface and exposed to sunlight much of the DOC can be mineralized to $\mathrm{CO}_{2}$, potentially providing a pathway to degrade otherwise passive permafrost carbon (e.g. Cory et al., 2013, 2014).

The quantity of carbon held in the northern hemispheric permafrost region is enormous but incubation experiments conducted on samples of this organic matter show that most of it is highly resistant to decay (Schädel et al., 2014). Discovering the actual physical and chemical mechanisms that stabilize permafrost soil carbon and assessing whether these mechanisms will be maintained as high-latitude ecosystems undergo radical change in the coming centuries is paramount 
for assessing the strength of the permafrost carbon cycle feedback. That these mechanisms remain poorly understood represents perhaps the greatest uncertainty in assessing the permafrost carbon feedback.

\section{Conclusions}

Here we have used a perturbed physic ensemble to place an uncertainty constraint on the release of carbon from permafrost soils. We find that by 2100 the permafrost region may release 56 (13 to 118 ) Pg C under RCP 2.6, 71 (16 to 146) Pg C under RCP 4.5, 74 (15 to 154) Pg C under RCP 6.0, and 102 (27 to 199) Pg C under RCP 8.5, with substantially more to be released under each scenario by 2300 . Of the six parameters perturbed the simulations are most sensitive in year 2100 to uncertainty in the size of the non-passive soil carbon pools and the equilibrium climate sensitivity. Additionally, by 2300 the transformation rate of the passive pool into carbon susceptible to decayed has become important. The simulations are insensitive to uncertainty in Arctic amplification, slow carbon pool overturning time, and the initial quality of carbon in the permafrost region. Our results suggest that a well-designed field campaign and set of incubation experiments intended to better constrain the size of the fast and slow carbon pools in permafrost soils could substantially reduced the uncertainty in the strength of the permafrost carbon cycle feedback. Contingent on our model structure being reflective of the natural world.

We have also projected a subset of a model variants 8000 years into the future, with simulations conducted to the year $10000 \mathrm{CE}$ under continued RCP 4.5 and 8.5 forcing. These simulations suggest that if permafrost survives in the high arctic, a new permafrost carbon pool may develop leading to a recovery of this carbon pool. Under higher forcing where near-surface permafrost ceases to exist outside Antarctica, the permafrost carbon pool nearly totally decays away over several thousand years. Overall our simulations suggest that the permafrost carbon cycle feedback to climate change will make a substantial contribution to climate change over the next centuries and millennia.

Acknowledgements. We are indebted to the efforts of the Permafrost Carbon Network for organizing the collection of data on permafrost carbon quantity and quality. G. Hugelius graciously provided the data for the map in Fig. 1. In particular we thank C. Schädel for providing additional data on the quality of permafrost carbon. We thank two anonymous reviewers for their helpful comments.

Edited by: T. Laurila

\section{References}

Archer, D.: A data-driven model of the global calcite lysocline, Global Biogeochem. Cy., 10, 511-526, 1996.

Archer, D.: Fate of fossil fuel $\mathrm{CO}_{2}$ in geologic time, J. Geophys. Res., 110, C09S05, doi:10.1029/2004JC002625, 2005.

Avis, C. A.: Simulating the present-day and future distribution of permafrost in the UVic Earth system climate model, $\mathrm{PhD}$. thesis, University of Victoria, 2012.

Avis, C. A., Weaver, A. J., and Meissner, K. J.: Reduction in areal extent of high-latitude wetlands in response to permafrost thaw, Nat. Geosci., 4, 444-448, doi:10.1038/ngeo1160, 2011.

Booth, B. B., Jones, C. D., Collins, M., Totterdell, I. J., Cox, P. M., Sitch, S., Huntingford, C., Betts, R. A., Harris, G. R., and Lloyd, J.: High sensitivity of future global warming to land carbon cycle processes, Environ. Res. Lett., 7, 024002, doi:10.1088/17489326/7/2/024002, 2012.

Burke, E. J., Hartley, I. P., and Jones, C. D.: Uncertainties in the global temperature change caused by carbon release from permafrost thawing, The Cryosphere, 6, 1063-1076, doi:10.5194/tc6-1063-2012, 2012.

Burke, E. J., Jones, C. D., and Koven, C. D.: Estimating the permafrost-carbon climate response in the CMIP5 climate models using a simplified approach, J. Climate, 26, 4897-4909, 2013.

Ciais, P., Sabine, C., Bala, G., Bopp, L., Brovkin, V., Canadell, J., Chhabra, A., DeFries, R., Galloway, J., Heimann, M., Jones, C., Quéé, C. L., Myneni, R. B., Piao, S., and Thornton, P.: Carbon and Other Biogeochemical Cycles, in: Working Group I Contribution to the Intergovernmental Panel on Climate Change Fifth Assessment Report Climate Change 2013: The Physical Science Basis, edited by: Stocker, T. F., Qin, D., Plattner, G.-K., Tignor, M., Allen, S. K., Boschung, J., Nauels, A., Xia, Y., Bex, V., and Midgley, P., Cambridge University Press, 2013.

Clark, P. U., Shakun, J. D., Marcott, S. A., Mix, A. C., Eby, M., Kulp, S., Levermann, A., Milne, G. A., Pfister, P. L., Santer, B. D., Schrag, D. P., Solomon, S., Stocker, T. F., Strauss, B. H., Weaver, A. J., Winkelmann, R., Archer, D., Bard, E., Goldner, A., Lambeck, K., Pierrehumbert, R. T., and Plattner, G.: Consequences of twenty-first-century policy for multi-millennial climate and sea-level change, Nature Climate Change, 6, 360-369, doi:10.1038/NCLIMATE2923, 2016.

Collins, M., Brierley, C., MacVean, M., Booth, B., and Harris, G.: The sensitivity of the rate of transient climate change to ocean physics perturbations, J. Climate, 20, 2315-2320, 2007.

Collins, M., Knutti, R., Arblaster, J. M., Dufresne, J.-L., Fichefet, T., Friedlingstein, P., Gao Jr., X., W. J. G., Johns, T., Krinner, G., Shongwe, M., Tebaldi, C., Weaver, A. J., and Wehner, M.: Long-term Climate Change: Projections, Commitments and Irreversibility, in: Working Group I Contribution to the Intergovernmental Panel on Climate Change Fifth Assessment Report Climate Change 2013: The Physical Science Basis, Cambridge University Press, 2013.

Cory, R. M., Crump, B. C., Dobkowski, J. A., and Kling, G. W.: Surface exposure to sunlight stimulates $\mathrm{CO}_{2}$ release from permafrost soil carbon in the Arctic, P. Natl. Acad. Sci. USA, 110, 3429-3434, 2013.

Cory, R. M., Ward, C. P., Crump, B. C., and Kling, G. W.: Sunlight controls water column processing of carbon in arctic fresh waters, Science, 345, 925-928, 2014. 
Cox, P. M., Betts, R. A., Jones, C. D., Spall, S. A., and Totterdell, I. J.: Modelling vegetation and the carbon cycle as interactive elements of the climate system, Proceedings of the RMS millennium conference, 2001.

Eby, M., Zickfeld, K., Montenegro, A., Archer, D., Meissner, K. J., and Weaver, A. J.: Lifetime of Anthropogenic Climate Change: Millennial Time Scales of Potential $\mathrm{CO}_{2}$ and Surface Temperature Perturbations, J. Climate, 22, 2501-2511, doi:10.1175/2008JCLI2554.1, 2009.

Forest, C. E., Stone, P. H., Sokolov, A. P., Allen, M. R., and Webster, M. D.: Quantifying uncertainties in climate system properties with the use of recent climate observations, Science, 295, 113-117, 2002.

Frölicher, T. L., Sarmiento, J. L., Paynter, D. J., Dunne, J. P., Krasting, J. P., and Winton, M.: Dominance of the Southern Ocean in anthropogenic carbon and heat uptake in CMIP5 models, J. Climate, 28, 862-886, 2014.

Fyke, J., Eby, M., Mackintosh, A., and Weaver, A.: Impact of climate sensitivity and polar amplification on projections of Greenland Ice Sheet loss, Clim. Dynam., 43, 2249-2260, 2014.

Fyke, J. G.: Simulation of the global coupled climate/ice sheet system over millennial timescales, $\mathrm{PhD}$ thesis, Victoria University of Wellington, 2011.

Gillett, N. P., Arora, V. K., Matthews, D., and Allen, M. R.: Constraining the ratio of global warming to cumulative $\mathrm{CO}_{2}$ emissions using CMIP5 simulations, J. Climate, 26, 6844-6858, 2013.

Helton, J. C. and Davis, F. J.: Latin hypercube sampling and the propagation of uncertainty in analyses of complex systems, Reliab. Eng. Syst. Safe. 81, 23-69, 2003.

Hugelius, G., Strauss, J., Zubrzycki, S., Harden, J. W., Schuur, E. A. G., Ping, C.-L., Schirrmeister, L., Grosse, G., Michaelson, G. J., Koven, C. D., O’Donnell, J. A., Elberling, B., Mishra, U., Camill, P., Yu, Z., Palmtag, J., and Kuhry, P.: Estimated stocks of circumpolar permafrost carbon with quantified uncertainty ranges and identified data gaps, Biogeosciences, 11, 6573-6593, doi:10.5194/bg-11-6573-2014, 2014.

Knutti, R. and Hegerl, G. C.: The equilibrium sensitivity of the Earth's temperature to radiation changes, Nat. Geosci., 1, 735743, 2008.

Knutti, R. and Rogelj, J.: The legacy of our $\mathrm{CO}_{2}$ emissions: a clash of scientific facts, politics and ethics, Climatic Change, 133, 361373, 2015.

Koven, C., Friedlingstein, P., Ciais, P., Khvorostyanov, D., Krinner, G., and Tarnocai, C.: On the formation of high-latitude soil carbon stocks: Effects of cryoturbation and insulation by organic matter in a land surface model, Geophys. Res. Lett., 36, L21501, doi:10.1029/2009GL040150, 2009.

Koven, C. D., Ringeval, B., Friedlingstein, P., Ciais, P., Cadule, P., Khvorostyanov, D., Krinner, G., and Tarnocai, C.: Permafrost carbon-climate feedbacks accelerate global warming, P. Natl. Acad. Sci. USA, 108, 14769-14774, doi:10.1073/pnas.1103910108, 2011.

Koven, C. D., Riley, W. J., and Stern, A.: Analysis of permafrost thermal dynamics and response to climate change in the CMIP5 Earth System Models, J. Climate, 26, 1877-1900, 2013.

Koven, C. D., Schuur, E. A. G., Schädel, C.,Bohn, T. J., Burke, E. J., Chen, G., Chen, X., Ciais, P., Grosse, G., Harden, J. W., Hayes, D. J., Hugelius, G., Jafarov, E. E., Krinner, G., Kuhry,
P., Lawrence, D. M., MacDougall, A. H., Marchenko, S. S., McGuire, A. D., Natali, S. M., Nicolsky, D. J., Olefeldt, D., Peng, S., Romanovsky, V. E., Schaefer, K. M., Strauss, J., Treat, C. C., and Turetsky, M.: A simplified, data-constrained approach to estimate the permafrost carbon-climate feedback, Philos. T. R. Soc. A, 373, 20140423, doi:10.1098/rsta.2014.0423, 2015.

MacDougall, A.: A modelling study of the permafrost carbon feedback to climate change: feedback strength, timing, and carbon cycle consequences, PhD thesis, University of Victoria, 2014.

MacDougall, A. H. and Friedlingstein, P.: The origin and limits of the near proportionality between climate warming and cumulative $\mathrm{CO}_{2}$ emissions, J. Climate, 28, 4217-4230, doi:10.1175/JCLI-D-14-00036.1, 2015.

MacDougall, A. H., Avis, C. A., and Weaver, A. J.: Significant existing commitment to warming from the permafrost carbon feedback, Nat. Geosci., 5, 719-721, doi:10.1038/NGEO1573, 2012.

MacDougall, A. H., Eby, M., and Weaver, A. J.: If anthropogenic $\mathrm{CO}_{2}$ emissions cease, will atmospheric $\mathrm{CO}_{2}$ concentration continue to increase?, J. Climate, 26, 9563-9576, doi:10.1175/JCLID-12-00751.1, 2013.

MacDougall, A. H., Zickfeld, K., Knutti, R., and Matthews, H. D.: Sensitivity of carbon budgets to permafrost carbon feedbacks and non- $\mathrm{CO}_{2}$ forcings, Environ. Res. Lett., 10, 125003, doi:10.1088/1748-9326/10/12/125003, 2015.

Matthews, H. D., Gillett, N. P., Stott, P. A., and Zickfeld, K.: The proportionality of global warming to cumulative carbon emissions, Nature, 459, 829-832, doi:10.1038/nature08047, 2009.

McKay, M. D., Beckman, R. J., and Conover, W. J.: Comparison of three methods for selecting values of input variables in the analysis of output from a computer code, Technometrics, 21, 239-245, 1979.

Moss, R. H., Edmonds, J. A., Hibbard, K. A., Manning, M. R., Rose, S. K., van Vuuren, D. P., Carter, T. R., Emori, S., Kainuma, M., Kram, T., Meehl, G. A., Mitchell, J. F. B., Nakicenovic, N., Riahi, K., Smith, S. J., Stouffer, R. J., Thomson, A. M., Weyant, J. P., and Wilbanks, T. J.: The next generation of scenarios for climate change research and assessment, Nature, 463, 747-754, doi:10.1038/nature08823, 2010.

Olson, R., Sriver, R., Goes, M., Urban, N. M., Matthews, H. D., Haran, M., and Keller, K.: A climate sensitivity estimate using Bayesian fusion of instrumental observations and an Earth System model, J. Geophys. Res.-Atmos., 117, D04103, doi:10.1029/2011JD016620,, 2012.

Orr, J., Najjar, R., Sabine, C., and Joos, F.: Abiotic-how-to, internal OCMIP report, LSCE/CEA Saclay, 1999.

Pierrehumbert, R.: Short-lived climate pollution, Annu. Rev. Earth Planet. Sci., 42, 341-379, 2014.

Schädel, C., Schuur, E. A., Bracho, R., Elberling, B., Knoblauch, C., Lee, H., Luo, Y., Shaver, G. R., and Turetsky, M. R.: Circumpolar assessment of permafrost $\mathrm{C}$ quality and its vulnerability over time using long-term incubation data, Glob. Change Biol., 20, 641-652, 2014.

Schaefer, K., Zhang, T., Bruhwiler, L., and Barrett, A. P.: Amount and timing of permafrost carbon release in response to climate warming, Tellus, 63B, 165-180, doi:10.1111/j.16000889.2011.00527.x, 2011.

Schaphoff, S., Heyder, U., Ostberg, S., Gerten, D., Heinke, J., and Lucht, W.: Contribution of permafrost soils to the global car- 
bon budget, Environ. Res. Lett., 8, 014026, doi:10.1088/17489326/8/1/014026, 2013.

Schmidt, M. W. I.,d Torn, M. S., Abiven, S., Dittmar, T., and Guggenberger, G., Janssens, I. A., Kleber, M., Kögel-Knabner, I., Lehmann, J., Manning, D. A. C., Paolo, N., Rasse, D. P., Weiner, S., Trumbore, S. E.: Persistence of soil organic matter as an ecosystem property, Nature, 478, 49-56, 2011.

Schmittner, A., Oschlies, A., Matthews, H. D., , and Galbraith, E. D.: Future changes in climate, ocean circulation, ecosystems, and biogeochemical cycling simulated for a business-as-usual $\mathrm{CO}_{2}$ emission scenario until year $4000 \mathrm{AD}$, Global Biogeochem. Cy., 22, GB1013, doi:10.1029/2007GB002953, 2008.

Schneider von Deimling, T., Meinshausen, M., Levermann, A., Huber, V., Frieler, K., Lawrence, D. M., and Brovkin, V.: Estimating the near-surface permafrost-carbon feedback on global warming, Biogeosciences, 9, 649-665, doi:10.5194/bg-9-649-2012, 2012.

Schneider von Deimling, T., Grosse, G., Strauss, J., Schirrmeister, L., Morgenstern, A., Schaphoff, S., Meinshausen, M., and Boike, J.: Observation-based modelling of permafrost carbon fluxes with accounting for deep carbon deposits and thermokarst activity, Biogeosciences, 12, 3469-3488, doi:10.5194/bg-12-34692015, 2015.

Scholes, R. and de Colstoun, E. B.: ISLSCP II Global gridded soil characteristics, available at: http://www.daac.ornl.gov, last access: 2 May 2012.

Schuur, E., McGuire, A., Schädel, C., Grosse, G., Harden, J., Hayes, D., Hugelius, G., Koven, C., Kuhry, P., Lawrence, D., Natali, S. M., Olefeldt, D., Romanovsky, V. E., Schaefer, K., Turetsky, M. R., Treat, C. C., and Vonk, J. E.: Climate change and the permafrost carbon feedback, Nature, 520, 171-179, 2015.

Schuur, E. A. G., Bockheim, J., Canadell, J. G., Euskirchen, E., Field, C. B., Goryachkin, S. V., Hagemann, S., Kuhry, P., Lafleur, P. M., Lee, H., Mazhitova, G., Nelson, F. E., Rinke, A., Romanovsky, V. E., Shiklomanov, N., Tarnocai, C., Venevsky, S., Vogel, J. G., and Zimov, S. A.: Vulnerability of Permafrost Carbon to Climate Change: Implications for the Global Carbon Cycle, BioScience, 58, 701-714, 2008.
Serreze, M. C. and Barry, R. G.: Processes and impacts of Arctic amplification: A research synthesis, Global Planet. Change, 77, 85-96, 2011.

Shiogama, H., Watanabe, M., Yoshimori, M., Yokohata, T., Ogura, T., Annan, J. D., Hargreaves, J. C., Abe, M., Kamae, Y., O'ishi, R., Rei, N., Seita, E., Toru, N., Ayako, A.-O., and Masahide, K.: Perturbed physics ensemble using the MIROC5 coupled atmosphere-ocean GCM without flux corrections: experimental design and results, Clim. Dynam., 39, 3041-3056, 2012.

Smith, L.: Chaos: a very short introduction, Oxford University Press, 2007.

Steinacher, M., Joos, F., and Stocker, T. F.: Allowable carbon emissions lowered by multiple climate targets, Nature, 499, 197-201, 2013.

Tarnocai, C., Canadell, J. G., Schuur, E. A. G., Kuhry, P., Mazhitova, G., , and Zimov, S.: Soil organic carbon pools in the northern circumpolar permafrost region, Global Biogeochem. Cy., 23, GB2023, doi:10.1029/2008GB003327, 2009.

Trumbore, S.: Age of soil organic matter and soil respiration: radiocarbon constraints on belowground C dynamics, Ecol. Appl., 10, 399-411, 2000.

Weaver, A. J., Eby, M., Wiebe, E. C., and P. B. Duffy, C. M. B., Ewen, T. L., Fanning, A. F., Holland, M. M., MacFadyen, A., Matthews, H. D., Meissner, K. J., Saenko, O., Schmittner, A., Wang, H., and Yoshimori, M.: The UVic Earth System Climate Model: Model description, climatology, and applications to past, present and future climates, Atmosphere-Ocean, 39, 1-67, 2001.

Zhuang, Q., Melillo, J. M., Sarofim, M. C., Kicklighter, D. W., McGuire, D., Felzer, B. S., Sokolov, A., Prinn, R. G., Steudler, P. A., and $\mathrm{Hu}, \mathrm{S}$.: $\mathrm{CO}_{2}$ and $\mathrm{CH}_{4}$ exchanges between land ecosystems and the atmosphere in northern high latitudes over the 21st century, Geophys. Res. Lett., 33, L17403, doi:10.1029/2006GL026972, 2006.

Zickfeld, K., Eby, M., Matthews, H. D., and Weaver, A. J.: Setting cumulative emissions targets to reduce the risk of dangerous climate change, P. Natl. Acad. Sci. USA, 106, 16129-16134, doi:10.1073/PNAS.0805800106, 2008. 